Revista Destaques Acadêmicos, Lajeado, v. 9, n. 1, 2017. ISSN 2176-3070

DOI: http://dx.doi.org/10.22410/issn.2176-3070.v9i1a2017.1270

www.univates.br/revistas

\title{
FATORES INFLUENCIADORES E O MERCADO DE PNEUS TRUCK NO RIO GRANDE DO SUL
}

\author{
Marcelo Lovato ${ }^{1}$, Samuel Martim de Conto ${ }^{2}$
}

Resumo: Diante das contínuas e cada vez mais ávidas mudanças de mercado, há uma grande necessidade de que os gestores conheçam as ameaças e oportunidades existentes no mercado como um todo para poder identificar seus pontos de melhorias e suas qualidades, buscando se adaptar a este ambiente competitivo. Conhecer seus clientes, sua região de atuação, seus concorrentes e todos os fatores influenciadores de seu mercado já não bastam. Portanto, o presente estudo teve como objetivo identificar os principais fatores que podem influenciar na decisão de compra dos clientes de pneus Truck no Estado do Rio Grande do Sul. Neste estudo quantitativo de caráter exploratório e descritivo foram pesquisados 90 clientes de parte da carteira da empresa Comercial e Importadora de Pneus Ltda. Foi identificado que dentre as necessidades consideradas mais importantes por esse público consumidor, o serviço de suporte técnico é uma carência da maioria deles. Outras necessidades também consideradas importantes pelos respondentes foram o serviço de montagem de pneus e o veículo de assistência à frota, onde ambos deveriam ser fornecidos pelo revendedor. O serviço de recapagem também foi mencionado com menor expressividade. Outro influenciador identificado foi a importância do fator humano, onde os respondentes identificaram como principal característica do vendedor ideal o conhecimento técnico do produto, seguido pelo pós-venda.

Palavras-chave: Pneus Truck. Decisão de Compra. Mercado. Rio Grande do Sul.

\section{INTRODUÇÃO}

Diante das contínuas e cada vez mais ávidas mudanças de mercado, há necessidade de que os gestores conheçam as ameaças e oportunidades existentes no mercado como um todo, para poder identificar seus pontos de melhorias e suas qualidades, buscando se adaptar a esse ambiente competitivo. Conhecer seus clientes, sua região de atuação, seus concorrentes e todos os fatores influenciadores de seu mercado já não bastam mais.

1 Acadêmico do curso de Administração da Univates, Lajeado-RS.

2 Professor do curso de Administração da Univates, Lajeado-RS. 
Em conhecimento desses fatos, faz-se necessária uma busca contínua por diferenciação, qualidade e inovação, para que as organizações e seus gestores sejam capazes de satisfazerem as expectativas e necessidades de seus clientes, cada vez mais exigentes e informados.

Segundo dados da ANIP (Associação Nacional da Indústria de Pneumáticos, texto digital) o mercado de pneus no Brasil vem caindo desde 2015. Já no primeiro trimestre de 2016, a queda no setor automobilístico influenciou negativamente o mercado de pneus, que reduziu $22 \%$ em relação ao primeiro período do ano passado, seguindo a mesma queda nos demais segmentos e mercado de reposição.

A simples realidade desse novo cenário desafia intensamente os gestores que atuam no segmento, pois compreender as necessidades do número menor de clientes que estão consumindo, será fator determinante para o sucesso no negócio. Além disso, diversos fatores alteraram o panorama econômico do setor industrial no país e no estado, frustrando as expectativas mais otimistas no curto prazo. Portanto desenvolver estratégias e ações para aumentar o faturamento, melhorar a rentabilidade e reter mais clientes, requer um maior conhecimento do mercado de atuação.

A indústria de pneus no país é concentrada em grandes fabricantes de pneus, em sua maioria multinacionais atuantes em diversos segmentos deste mercado. Eles são conhecidos no mercado pelas marcas Goodyear, Pirelli, Bridgestone, Firestone, Michelin, Continental, Dunlop, Titan, que são empresas multinacionais, e Magion, Rinaldi, Levorin e Tortuga, fabricantes nacionais. Parte deste mercado é tomada pelos pneus importados de outros países, os quais se mantêm no mercado interno com preços mais baixos e com produtos em sua maioria de qualidade inferior, mas que por muitos momentos se fizeram necessários para suprir a demanda maior que a oferta interna.

As vendas que acontecem neste ramo são destinadas a três segmentos distintos: mercado externo, as montadoras e o mercado de reposição interno, o qual será o motivo e alvo da pesquisa, mais especificamente com uma parte dos clientes deste mercado, os quais residem ou tem empresas situadas no Estado do Rio Grande do Sul.

$\mathrm{O}$ mercado de pneus que experimentou um vigoroso crescimento nos últimos anos vem passando por grandes dificuldades devido à atual crise econômica, pois a fatia do mercado que atende as montadoras sofreu significativa queda nas vendas acompanhando ao comportamento da venda de veículos no País. O mercado de reposição tende a suprir esta baixa, porém a forte desaceleração econômica não permitiu ao mercado manter esta perspectiva. Assim, surge a necessidade de conhecer os concorrentes atuantes no mercado de pneus do Rio Grande do Sul, assim como a maneira que estão traçando suas estratégias e ações para se manterem nesse mercado e sua carteira de clientes. 
Diante do exposto, este estudo visa a conhecer melhor os clientes do mercado de pneus Truck do estado do Rio Grande do Sul, considerando, todos os pneus de caminhão utilizados no ramo de transportes de carga e passageiros. Os clientes são parte da carteira ativa da empresa Comercial e Importadora de Pneus Ltda, afiliada na cidade de Lajeado/RS desde 2002, tendo como intuito de pesquisa apresentar subsídios que possam contribuir para os gestores que atuam nesse mercado.

Levando em consideração as constantes mudanças no mercado, a empresa necessita se adaptar para atender às necessidades do consumidor. Diante disso o trabalho procura responder a seguinte questão: atualmente, quais as principais necessidades dos clientes de pneus Truck no estado do RS?

O segmento de pneus é dividido em cinco famílias de produtos, as quais são denominadas da seguinte forma:

1) Linha de produtos Car, que são todos os pneus destinados a linha de veículos passeio;

2) Linha de pneus Suv (utilitários médios) e Vans (pequenos veículos para transportes de cargas ou passageiros);

3) Linha de produtos Agrícola, que são pneus para uso no segmento fora de estrada, como máquinas agrícolas e implementos;

4) Linha de pneus Moto, destinados aos veículos duas rodas;

5) Linha de pneus Truck, conhecida também pelos fabricantes como pneus gigantes, os quais os pneus são destinados a todos os tipos de veículos de carga, de utilização comercial, do tipo denominados como caminhões, carretas, reboques e semi-reboques.

O trabalho de pesquisa se delimitará ao segmento denominado Truck, e aos clientes da empresa Comercial e Importadora de Pneus Ltda., sediada no município de Lajeado/RS, atendidos nesse segmento. Os clientes que fizeram parte do estudo são somente consumidores finais, sejam eles autônomos ou empresas frotistas (proprietários de um número maior de veículos de transporte), e que residam no estado do Rio Grande do Sul. A pesquisa foi aplicada somente a clientes com cadastro ativo, que possuíam em seu cadastro algum contato por e-mail e que tenha algum histórico de compras inferior a dois anos da data de realização deste.

O objetivo geral deste estudo é o de identificar os principais fatores que podem influenciar na decisão de compra dos clientes de pneus Truck no Estado do Rio Grande do Sul. Os objetivos específicos são os seguintes: identificar as necessidades e os principais fatores de influência na decisão de compra dos pneus Truck; identificar as empresas revendedoras de pneus e marcas presentes, que atuam no mesmo ramo no Estado do Rio Grande do Sul.

Em um cenário econômico em crescimento normal uma pesquisa de mercado já tem grande relevância, porém em um momento de encolhimento 
econômico e queda nas vendas, conhecer os clientes, suas necessidades e novos hábitos, podem ser fator determinante para a sobrevivência no mercado. Isso permite ao gestor aumentar a assertividade de suas ações, compreender melhor as expectativas do mercado de pneus e identificar quais são os principais fatores que influenciam na decisão dos consumidores deste produto.

Poder entender as diferentes necessidades do segmento, as particularidades de cada região, conhecer os principais concorrentes, e entender qual a importância que cada cliente dá às diversas variáveis influenciadoras, são fatores primordiais a qualquer gestor.

Um novo ciclo na comercialização de pneus se iniciou, e nele ocorreram mudanças de duas naturezas: econômicas e mercadológicas, e estimuladas por um ambiente econômico desfavorável, fazem com que as empresas necessitem utilizar de muito empenho e de todas as informações disponíveis para superar os obstáculos por ele impostos.

Este estudo se justifica pelas informações que foram obtidas através da pesquisa, para a expansão e manutenção da carteira de clientes de qualquer organização do ramo. As informações poderão auxiliar para o planejamento estratégico, podendo otimizar e aperfeiçoar suas ações, ganhando tempo e dinheiro direcionando o foco da empresa de acordo com a demanda atual dos clientes.

\section{REFERENCIAL TEÓRICO}

\subsection{Conceito e composto de Marketing}

O marketing não é apenas propaganda, mas sim todo o processo de desenvolvimento do produto, venda, entrega ao consumidor, impacto no ambiente e na sociedade. O marketing interliga todos os departamentos de uma empresa, desde a compra da matéria prima, o desenvolvimento, a venda, a satisfação do cliente e o pós-vendas.

“O marketing envolve a identificação e a satisfação das necessidades humanas e sociais" (KOTLER; KELLER, 2012, p. 3). Marketing é a habilidade de modificar uma necessidade em uma oportunidade lucrativa. O marketing é a área do conhecimento que engloba todas as atividades referentes às relações, visando alcançar objetivos em comum, considerando sempre o meio ambiente de atuação e o impacto que essas relações causam na sociedade (LAS CASAS, 2011).

Kotler (2000, p. 30) menciona que "o objetivo do Marketing é tornar a venda supérflua" [...] "conhecer e compreender tão bem o cliente que o produto ou serviço se adapte a ele e se venda por si só".

Conforme definem os autores citados anteriormente, a satisfação dos clientes, a competitividade duradoura e junção de esforços são fatores 
julgados por todos, como relacionados com marketing, consequentemente uma ferramenta primordial a qualquer gestor nos dias atuais, e dominar estes conceitos e ter a capacidade de aplicar os mesmos em sua gestão é um grande desafio.

O marketing na sua abrangência é composto por 5 (cinco) essências. Os produtos ou serviços; a sua praça, centro de distribuição ou área atendida; a promoção, que tem como objetivo chamar a atenção dos consumidores; o preço; e as pessoas, que é o principal foco do marketing. Abaixo detalharemos um pouco mais de cada composto de marketing, com intuito de deixar muito bem explícito a importância de cada um deles para o estudo como um todo.

Produto: um produto é uma oferta que satisfaz uma necessidade ou desejo, podendo ser ele um bem, um evento, um serviço, um lugar, uma ideia (KOTLER, 2000). É qualquer objeto que pode ser oferecido ao mercado, para ser usado ou apreciado. Ele é desenvolvido para atender necessidades e desejos do consumidor.

Praça: a praça está relacionada aos canais de distribuição dos produtos, na maneira como o produto chegará até o consumidor (KOTLER, 2000). O ponto de distribuição de um produto no mercado tem um papel importante, pois é a partir da distribuição que o consumidor terá acesso ao produto. É um espaço público que propicie convivência para os usuários. Um local onde seu produto é exposto constantemente.

Promoção: a promoção compreende as ações de marketing que despertem a atenção do público consumidor para os produtos da empresa (KOTLER, 2000). Inclui a propaganda, as relações públicas a promoção de vendas. Tem como objetivo atrair a atenção do consumidor para o seu produto.

Preço: o preço refere-se aos valores estabelecidos para a comercialização dos produtos. Deve preocupar-se com o valor agregado percebido pelo cliente, o valor gasto pela empresa para sua produção, a oferta e a demanda do mercado, os preços praticados pela concorrência, além de descontos e prazos de pagamentos (KOTLER, 2000). Visa atender a demanda e maximizar a oferta.

Pessoas: refere-se às pessoas da organização. São elas que interagem diretamente com os clientes, fornecedores, e que dão alma a empresa. As pessoas são a imagem da empresa (KOTLER, 2000, KOTLER; KELLER, 2012).

Esses cinco componentes são essenciais para um relacionamento comercial de sucesso. A venda de sucesso não é aquela que simplesmente gera lucro para a empresa, mas sim, aquela venda em que todas as partes saem satisfeitas. A parte do cliente, por ter suprido sua necessidade e desejo, a parte do vendedor, pois finalizou uma venda e iniciou um relacionamento comercial, que se cultivado poderá lhe trazer muito mais vendas e clientes, uma vez que o cliente bem atendido difunde a informação no mercado. 


\subsection{Análise do ambiente: macroambiente e microambiente}

Para que haja uma venda de sucesso, onde todas as partes ficam satisfeitas, é necessária uma análise das mudanças do mercado no qual uma empresa está inserida. Isso visa evidenciar qualquer tipo de ameaça ou oportunidade à organização, e permite que identificar informações como: com que frequência os donos de transportadoras têm efetuado suas compras de pneus? Qual o segmento se encontra menos afetado pelo momento econômico que enfrentamos atualmente? Qual a necessidade deste cliente não está sendo atendida neste momento? (CHURCHILL, 2010).

O ambiente externo da empresa é formado pelo macroambiente. No ambiente externo chamado de "Mercado", são as forças sobre as quais os gestores não têm o poder de interferir. A economia, a política, as leis, o ambiente, a sociedade na qual a empresa está inserida, os avanços tecnológicos são exemplos de agentes externos que afetam as atividades de uma organização. Conforme destaca Las Casas (2011) é necessário se adaptar da melhor forma possível às mudanças impostas por eles e para o bom andamento dos negócios.

Já o microambiente, é formado pelo ambiente interno da empresa. São forças sobre as quais os gestores têm o poder para interferir. O produto ou o serviço, a praça e a distribuição, a promoção, a gestão. São exemplos de agentes internos relacionados com as atividades da organização, os quais o gestor tem o poder de modificar, fazendo as correções que julgar necessárias para o melhor andamento dos negócios (LAS CASAS, 2011).

Conforme aponta Churchill (2010, p. 28) "numa economia de crescimento mais lento, os profissionais do marketing podem conhecer melhor seus clientes para criar valor". Durante um longo período de recessão, com considerável queda na demanda, em paralelo a um aumento no desemprego. Por esse motivo, os consumidores necessitam se adaptar a essa nova realidade e consumem menos, limitando-se a comprar somente o necessário e procurando o melhor negócio, tornando o mercado de consumo muito mais disputado e concorrido (CHURCHILL, 2010).

Para Kotler e Keller (2012, p. 38) "uma administração de marketing bem sucedida requer determinadas capacidades como: entender, criar, entregar e manter o valor para o cliente". O marketing estratégico estabelece os mercadosalvo e a proposta de valor a ser oferecida com base em uma análise das melhores oportunidades de mercado.

"Planejamento estratégico é o processo gerencial de desenvolver e manter uma direção estratégica que alinhe as metas e os recursos da organização com suas mutantes oportunidades de mercado" (LAS CASAS, 2011, p. 3). Desta forma, planejar estrategicamente é estar em sintonia com o mercado e com as necessidades de seu consumidor, visando realizar as adaptações necessárias, considerando os recursos disponíveis e objetivos almejados, tendo o máximo de informações disponíveis para tornar as decisões do gestor mais assertivas. 
Essas informações são obtidas pelos profissionais de marketing por meio de fontes internas ou externas. Como fontes internas, são exemplos o histórico de vendas, cadastro dos clientes e demais informações, que deixa evidente o que vende e a quem se vende naquele determinado momento, ou mesmo a quem já se vendeu e hoje não vende mais. Informações contábeis também revelam produtos com maior lucratividade e são também uma fonte interna. A criação de sistemas para assegurar o registro destas informações é muito importante, pois quando necessário as informações internas básicas são o ponto inicial para qualquer ação da organização (CHURCHILL, 2010).

Portanto, se faz necessário conhecer as fontes de informações externas, pois é necessário saber o que ocorre no ambiente externo para tomar as decisões corretas. Para isso é necessário conhecer todas as fontes influenciadoras ao ambiente externo, como a economia, as leis, os concorrentes, os clientes atuais e futuros e muito mais. Tais informações podem ser coletadas de diversas formas, como: publicações empresariais, grupos profissionais, relatórios governamentais, pesquisa com clientes e serviços de pesquisas (CHURCHILL, 2010).

Churchill (2010, p. 117) distingue informação e dados:

Os profissionais de marketing precisam de informações, não apenas de dados, que são simplesmente fatos e estatísticas. Em contraste, informação refere-se a dados apresentados de maneira que sejam úteis para a tomada de decisões. Em geral isso significa que os dados são apresentados para mostrar a presença ou a ausência de alguma tendência ou padrão.

Em um mercado mais restrito de consumidores, estar a par de todas as fontes de informações sejam elas internas ou externas será fator decisivo para maior assertividade de ações do gestor na organização.

Nestes momentos em um mercado com grandes marcas fornecedoras de um determinado produto ou serviço, o preço e a qualidade do mesmo podem ser determinados pelo fabricante. Obtendo a maior fatia do mercado eles impõem o preço e a qualidade praticada, muitas vezes obrigando os consumidores a aceitarem a alteração feita (CHURCHILL, 2010).

Um comprador pode também forçar a baixa de preço ou melhoria de qualidade de um determinado produto ou serviço. Assim como um comprador pequeno se vê muitas vezes obrigado a aceitar mudanças impostas por grandes fornecedores, um comprador potencial pode forçar uma baixa de preço, devido a um grande volume que pode comprar; podendo também blefar para reduzir custos. Momentos difíceis como o que se encontra a economia atual também podem ajudar o comprador a barganhar um menor preço (CHURCHILL, 2010).

O mercado de pneus Truck é concorrido em todo o País, pois caracteriza-se um produto com alto valor agregado e é um item de grande representatividade 
nos custos de um transportador. O consumidor que necessita fazer a reposição do produto pneu em sua frota pode adquiri-lo basicamente de dois tipos de fornecedores que atuam neste segmento, denominados da seguinte forma:

Revendas: são revendedores em sua maioria de grande porte, os quais comprar o produto direto do fabricante, com grandes volumes, contratos de consumo e regiões de atuação pré-definidas.

Sub-revendas: são revendedores pouco menores, os quais têm como fornecedor as revendas. Geralmente atuam mais regionalmente, e as decisões de onde e de quem comprar dependem mais da melhor oferta e disponibilidade.

Ambos são fornecedores dos clientes consumidores de pneus Truck no Estado do RS, sendo que na maioria das vezes o que define a condição comercial praticada é o volume comercializado. Portanto, pode o consumidor, caso de maior porte, muitas vezes pagar menos que um subrevendedor. Desta forma, todas as vendas de pneus gigantes acontecem como vendas de atacado. No caso deste estudo, o foco abrange apenas a compra de pneus Truck para consumo.

Para Kerin (2007) mesmo com as tecnologias atuais disponíveis, ainda não se encontrou uma maneira de descentralizar as vendas pessoais. As relações interpessoais que ocorrem entre vendedor e comprador frequentemente podem influenciar a decisão de compra do consumidor. O comportamento dos profissionais envolvidos no processo de venda ao cliente são muitas vezes um forte fator influenciador de sua decisão de compra.

Nesse segmento, uma empresa não será fornecedora única, e possivelmente terá concorrentes. Dentre os papéis do profissional do marketing está o de descobrir o que seus concorrentes estão fazendo para poder prever suas ações futuras. Uma boa opção é criar valor para os clientes, diferenciando e customizando o atendimento, o que ajuda a empresa a ter uma vantagem competitiva perante os demais fornecedores do mercado (CHURCHILL, 2010).

A concorrência é um fenômeno onde vários agentes estão lutando por clientes, através do fornecimento de serviços ou produtos. A meta de toda empresa é ser exclusiva e ser lucrativa. De acordo com Kotler (1974), existem três tipos de concorrência, são elas:

- Concorrência genérica: “Ocorre entre todos os produtos capazes de satisfazer a mesma necessidade básica" (KOTLER, 1974, p. 331). Os produtos são caracterizados pela sua forma.

- Concorrência por tipo de produto: “A concorrência por tipo de produto existe entre produtos e marcas que tenham as mesmas formas e funções similares" (KOTLER, 1974, p. 332), como exemplo, os pneus variando em modelo, tamanho, qualidade e desempenho, e representam todos um mesmo produto. 
- Concorrência de empresas: "A concorrência de empresas ocorre entre as empresas que fornecem produtos similares" (KOTLER, 1974, p. 332), como exemplo, os revendedores de pneus e fabricantes, como: Pirelli, Michelin, Bridgestone e Firestone, que competem entre si.

Kotler e Keller (2012) explicam que pode ocorrer concorrência entre diferentes grupos estratégicos, principalmente quando buscam o mesmo mercado consumidor, dessa forma a empresa precisa obter informações sobre as estratégias de marketing, produção, pesquisa e desenvolvimentos, finanças e recursos humanos dos concorrentes. Além dos fatores como qualidade, compostos de produtos, serviços ao consumidor, políticas de preços, coberturas de distribuição e promoção de vendas.

No mercado de pneus no Rio Grande do Sul, assim como no restante de nosso país, tem-se uma concorrência muito forte, que acentuada pelo momento de recessão nas compras, se torna muito mais ostensiva diante todos atuantes. Não sendo possível precisar a demanda de um determinado mercado, as organizações vêm utilizando serviços especializados como: economistas, estatísticos e grupos comerciais, buscando uma maior assertividade em suas ações (CHURCHILL, 2010).

Ainda segundo Churchill (2010, p. 105), "para estimar a demanda atual de um setor, uma abordagem eficiente, é usar dados disponíveis de serviços de pesquisas de marketing e grupos comerciais do setor". Em um mercado extremamente competitivo como o mercado de pneus, se adaptarem para atender com precisão a necessidade de cada cliente é um grande desafio, compreender a demanda dos clientes do mercado nesse momento aumenta muito a assertividade das ações de um gestor.

Conforme aborda Kotler (2007), o objetivo do marketing é atender e satisfazer as necessidades e desejos de um determinado público alvo. O comportamento do consumidor é a área em que estuda como as pessoas compram, utilizam e descartam os produtos ou serviços. Entender o comportamento do consumidor é algo amplo e complexo, pois é preciso perceber o que o consumidor quer, compreendendo suas reais motivações e preferências.

O comportamento do consumidor é definido como a verificação das atividades diretamente envolvidas em obter, consumir e dispor de produtos e serviços, incluindo os processos decisórios que antecedem e sucedem estas ações. É o processo vivido pelos indivíduos, que ao tomarem decisões de empregar seus recursos disponíveis em itens relacionados ao consumo, fazem uma vinculação com os propósitos dos profissionais de marketing, que buscam identificar as necessidades e induzir o cliente a necessitar do produto ou serviço (SCHIFFMAN; KANUK, 2000).

Para ter sucesso, o profissional de vendas precisa ir além do conhecimento das variáveis influenciadoras, e entender realmente como eles tomam suas 
decisões, compreender o processo de compra como um todo, e identificar o real tomador de decisão do ato da compra (KOTLER, 2000).

A decisão de compra do consumidor depende de vários fatores, o dia, os gostos, a situação financeira do individuo, a economia do mercado, as condições de pagamento e, até mesmo o estoque e a logística de uma empresa. Se o cliente tiver urgência no produto/serviço, ele não vai esperar para ter o produto no estoque ou a disponibilidade do serviço, vai procurar outra empresa que oferta o mesmo produto ou que disponibiliza serviços semelhantes. $\mathrm{O}$ atendimento também é um ponto fortíssimo na decisão de compra, o bom atendimento é decisivo para finalizar a venda com sucesso.

Baseado no referencial citado percebe-se que a pesquisa de mercado na atual conjuntura econômica do País, constitui uma importante ferramenta que auxilia os gestores em suas decisões e planejamento. Assim, conhecer bem as necessidades, hábitos e costumes de seus clientes são elementos importantes para uma organização que busca o sucesso, da mesma forma que conhecer seus concorrentes e suas estratégias faz mais assertiva a condução do negócio realizada pelo gestor da organização.

\subsection{Perspectivas do mercado de pneus}

A palavra mercado possui diversos significados, conforme diz Chiavenato (2005), mercado é o local físico, onde as pessoas fazem suas compras e vendas de produtos e serviços, é um conjunto de consumidores e fornecedores, relacionados por uma transação de oferta e procura, e as ferramentas para analisar o mercado, visam a fornecer informações para guiar o gestor e as organizações em sua tomada de decisão.

De acordo com a Associação Nacional da Indústria de Pneumáticos (ANIP), a situação atual do mercado de pneus no país passa por um momento de mudança, pela qual os grandes fabricantes têm tido muita dificuldade em se adaptar e serem assertivos em suas ações, pois só este setor empregou diretamente 28.500 empregados em 2015, sendo 120 mil empregados indiretos, além de 40 mil pontos de vendas no país. A Figura 1 mostra a variação das vendas dos últimos nove anos no Brasil. 
Figura 1 - Gráfico da variação das vendas dos últimos nove anos no Brasil

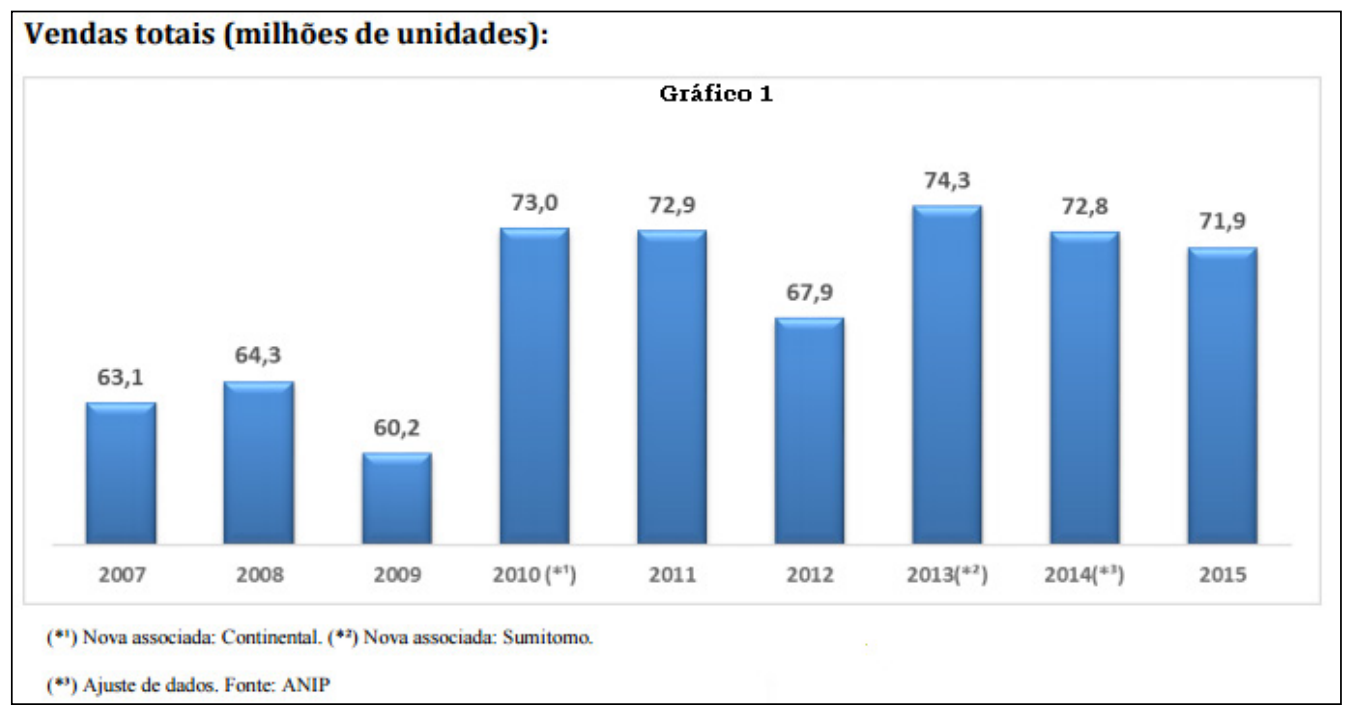

Fonte: ANIP (2016).

Segundo a ANIP (2016) a variação no mercado também aconteceu com as mudanças da economia, que afetou o mercado da indústria de veículos e, consequentemente, vem mudando o cenário das vendas de pneus no país, uma vez que grande parte da produção são destinadas às montadoras.

\section{PROCEDIMENTOS METODOLÓGICOS}

Este estudo foi realizado em duas etapas, uma primeira etapa exploratória, e a segunda etapa como descritiva. Segundo Gil (1999), a pesquisa exploratória tem como finalidade desenvolver, esclarecer e modificar conceitos e ideias, proporcionando uma visão geral sobre o tema. Com este estudo foram identificados os principais fatores influenciadores na decisão de compra no ramo de pneus novos no RS. A etapa exploratória contemplou o desenvolvimento do modelo de levantamento dos dados aplicados.

Quanto à pesquisa de forma descritiva, conforme Malhotra (2011, p. 59) "é um tipo de pesquisa conclusiva que possui como principal objetivo a descrição de algo". A pesquisa descritiva expõe de forma clara o problema, com a especificação das informações de maneira estruturada, com base no referencial teórico e em forma de questionário.

Quanto aos procedimentos técnicos, trata-se de uma pesquisa de campo. Para Malhotra (2011), os métodos de levantamento de campo se caracterizam pela simplicidade e confiabilidade, os questionários são fáceis de ser aplicados, utilizando questões caracterizadas como fechadas e questões abertas, para uma maior e mais abrangente análise e interpretação dos dados. 
Em relação à natureza da abordagem, trata-se de uma pesquisa quantitativa, que se propõe identificar e analisar, através da aplicação de questionários, quais os principais fatores que influenciam na decisão de compra no ramo de pneus Truck do RS. Este tipo de pesquisa busca quantificar os dados, envolvendo alguma forma de análise estatística. E as pesquisas deste formato, podem ser consideradas conclusivas (MALHOTRA, 2011). O levantamento de dados no modo survey, para Malhotra (2011), é um método que utiliza o interrogatório dos participantes, na forma de perguntas sobre o seu meio, intenções, comportamentos.

Neste estudo, o levantamento dos dados ocorreu em duas etapas. Na primeira etapa as questões foram desenvolvidas com base no referencial teórico, onde foram realizadas entrevistas em profundidade com consumidores do segmento, que puderam expor seu conhecimento, comportamento, crenças e opiniões relacionadas ao mercado de pneus Truck. Baseada nesta primeira etapa e no referencial do estudo, foi estruturado um questionário com caráter descritivo, com 15 (quinze) questões fechadas, as quais os respondentes puderam optar por uma das alternativas disponíveis, ou ainda oferecerem suas próprias respostas, possibilitando divergências nas opiniões (GIL, 2010).

A população alvo deste estudo é composta pelos clientes ativos que consomem pneus Truck (para caminhões). Os questionários foram enviados através do correio eletrônico, oferecendo 15 dias úteis para o retorno da pesquisa. Conforme Vergara (2013), a população alvo envolve os sujeitos do estudo, ou seja, serão as pessoas que fornecerão os dados necessários ao pesquisador, esses dados serão quantitativamente analisados e interpretados, utilizando ferramentas estatísticas por meio da planilha de Excel.

Qualquer estudo apresenta limitações e possibilidades, motivo pelo qual Vergara (2007), recomenda que se deve antecipar às críticas, informando as limitações. Entre as limitações destaca-se o fornecimento de respostas que podem não traduzir opiniões reais, por razões conscientes e inconscientes, podendo dificultar a análise. Este estudo ocorreu de forma sigilosa, pois não citou ou divulgou nomes de empresas e de participantes.

\section{APRESENTAÇÃO E ANÁLISE DOS RESULTADOS}

O propósito deste capítulo é apresentar os resultados da pesquisa realizada com 90 clientes de parte da carteira da empresa Comercial e Importadora de Pneus Ltda. Foi realizada a interpretação dos dados coletados, a fim de identificar e responder aos objetivos propostos.

\subsection{Resultados das entrevistas em profundidade}

Na realização das entrevistas em profundidade, os respondentes foram selecionados para que as respostas cruzassem com o tema e objetivos do estudo. Por esse motivo, os quatro respondentes desta pesquisa são empresários donos 
de empresas de transportes de cargas e passageiros, os quais não participaram da segunda etapa deste estudo.

Foi questionado aos respondentes quanto aos principais fatores que os influenciam na escolha de onde comprar os pneus que necessitam. Os fatores mais mencionados foram lembrados na seguinte ordem: em primeiro a qualidade e aceitação de mercado do produto vendido, em segundo o rendimento do mesmo e em terceiro o preço de venda do produto. Estes três fatores foram citados em todas as pesquisas em profundidade, demonstrando o grau de importância do consumidor para com estas variáveis.

Perguntando sobre a influência do atendimento na escolha de onde comprar, foi obtido de todos os respondentes a mesma resposta: um dos principais fatores está relacionado às pessoas, ao indivíduo, que pode vir a ser fator decisivo de quem e onde comprar.

Quanto aos fornecedores e marcas de pneus dos respondentes, foram identificados os seguintes produtos, na respectiva ordem: Campneus, Dipesul, Digal, Dpaschoal, M2 Pneus e Excelsior Pneus. Dentre as marcas mencionadas: Pirelli, Michelin, Goodyear, Bridgestone, Firestone, Continental e Dunlop.

Foi solicitado que fossem determinadas as principais características do vendedor ideal de pneus, e obteve-se as seguintes respostas: conhecimento técnico de produto, cordialidade, e boa apresentação. Quanto às características de um fornecedor ideal, foram mencionados: prazo de pagamento, preço competitivo, produto de qualidade, entrega rápida e serviço de pós-venda.

Foi indagado aos respondentes sobre suas necessidades de serviços não oferecidas por seu fornecedor de pneus, e que se ofertadas influenciariam na sua decisão de onde comprar e obteve-se as seguintes colocações: serviço de suporte técnico, montagem de pneus, recapagem e veículo de assistência na frota.

Essas respostas obtidas das entrevistas em profundidade, além do referencial teórico, foram desenvolvidas as questões do questionário para a segunda etapa (levantamento).

\subsection{Resultados do levantamento}

Para caracterização do perfil do cliente, utilizaram-se as variáveis: tipo de transportador, setor de transportes a qual pertence, cargo atual na empresa, número de veículos na frota, e cidade onde reside.

Quanto ao tipo de transportador, 66,7\% dos 90 entrevistados tem constituída pessoa jurídica, empresa de transportes, e 33,3\% dos respondentes são transportadores autônomos, que atuam no mercado ainda como pessoa física. Pode-se concluir que a predominância de empresas na amostra da pesquisa se dá pela formalização dos relacionamentos de negócios, e maior 
exigência dos contratantes de serviços, que por muitas vezes só contratam empresas de transportes, e não mais autônomos.

Quanto ao setor de transportes a qual pertencem, $82,5 \%$ dos 90 entrevistados pertencem ao segmento de transporte de cargas, e 17,5\% dos respondentes são do segmento de transporte de passageiros. Um fator determinante da grande diferença da quantidade da amostra, pode se dar devido a predominância ao modal rodoviário, pois ainda é o principal meio logístico de transportes brasileiro, conforme consta no mapeamento de infraestrutura de transportes no Brasil, realizado pelo IBGE em 2009.

Quanto ao cargo do respondente e número de veículos da frota, identificou-se que $64 \%$ deles têm até 10 veículos, e os $36 \%$ restantes tem entre 11 a 270 veículos de transporte. Dos que responderam à pesquisa, 61,9\% eram os próprios proprietários da empresa, sendo que os $38,1 \%$ restantes, foram respondidos pelos compradores, responsáveis pela frota e/ou pelo caminhoneiro autônomo.

Essa pesquisa abrangeu respondentes de 29 municípios diferentes, sendo que os que tiveram maior incidência foram: Arroio do Meio, Lajeado, Santa Maria e Venâncio Aires. Isso pode ser justificado por todos fazerem parte da região de atuação da empresa utilizada como base para realizar a pesquisa, tendo como base de atendimento a filial sediada em Lajeado.

Os fornecedores, conforme os dados coletados na amostra estão apresentados na Tabela 1.

De acordo com os 90 entrevistados nesta pesquisa, os fornecedores de pneus mais lembrados foram a Campneus, DPaschoal e Dipesul. Foi possível identificar a presença de mais fornecedores além dos apontados pela base de dados do estudo.

Tabela 1 - $\mathrm{N}^{\circ}$ de citações dos fornecedores

\begin{tabular}{lcc}
\hline \multicolumn{1}{c}{ Fornecedores de Pneus } & $\mathbf{N}^{\circ}$ Citações & Percentual \\
\hline Campneus & 26 & 28,20 \\
DPaschoal & 23 & 25,60 \\
Outros & 23 & 25,60 \\
Dipesul & 16 & 17,90 \\
Excelsior Pneus & 2 & 2,60 \\
Digal Pneus & 0 & 0,00 \\
\hline
\end{tabular}

Fonte: Resultados do levantamento (2016).

As marcas de pneus mais presentes nas frotas, conforme os dados coletados na amostra, estão apresentadas na Tabela 2. 
Tabela 2 - $\mathrm{N}^{\circ}$ de citações das Marcas de Pneus

\begin{tabular}{lcc}
\hline \multicolumn{1}{c}{ Marcas de Pneus } & $\mathbf{N}^{\circ}$ Citações & Percentual \\
\hline Pirelli & 44 & 48,89 \\
Michelin & 23 & 25,56 \\
Goodyear & 9 & 10,00 \\
Firestone & 7 & 7,78 \\
Continental & 5 & 5,56 \\
Bridgestone & 5 & 5,56 \\
Outros & 5 & 5,56 \\
\hline
\end{tabular}

Fonte: Resultados do levantamento (2016).

Conforme a Tabela 2, observa-se uma presença mais expressiva dos pneus de marca Pirelli dentre os respondentes da pesquisa, que corresponderam a quase metade das marcas citadas. Conforme aborda Kotler (2007), a concorrência de marca por tipo de produto ocorre sempre que os mesmos tenham funções e formas similares, assim como as empresas que concorrem por fornecerem produtos similares.

Na Tabela 3 são apresentados os fatores que mais influenciam na decisão de compra.

Tabela 3 - $\mathrm{N}^{\circ}$ de citações dos fatores influenciadores

\begin{tabular}{lcc}
\hline \multicolumn{1}{c}{ Possíveis fatores de influência } & $\mathbf{N}^{\circ}$ Citações & Percentual \\
\hline Rendimento do Produto & 65 & 71,40 \\
Preço & 17 & 19,00 \\
Atendimento do Vendedor & 7 & 7,10 \\
Marca & 1 & 2,40 \\
Pós-venda & 0 & 0,00 \\
\hline
\end{tabular}

Fonte: Resultados do levantamento (2016).

Ficou evidente dentre os 90 entrevistados que o fator produto é o de maior peso na decisão de compra dos consumidores de pneus Truck. Diante dessa diferença, contata-se que o consumidor está muito mais preocupado e ter um produto com um melhor custo benefício, uma vez que nem sempre o de menor preço de compra, trará o melhor rendimento a longo prazo. Nesse mesmo sentido, Kotler (2000) afirma que um produto é uma oferta que satisfaz uma necessidade do cliente. Las Casas (2011) também afirma que o produto ou serviço são fatores de destaque para a concretização do negócio, portanto o fabricante que aperfeiçoar a qualidade do produto de acordo com a necessidade do consumidor, certamente terá destaque diferenciado no mercado. 
Dentre às principais características que o fornecedor ideal de pneus deva ter, conforme os dados coletados na amostra estão apresentados na Tabela 04 abaixo:

Tabela 4 - $\mathrm{N}^{\circ}$ de citações das principais características do revendedor ideal de pneus

\begin{tabular}{lcc}
\hline \multicolumn{1}{c}{ Características } & N $^{\circ}$ Citações & Percentual \\
\hline Produto de qualidade & 46 & 51,20 \\
Preço & 28 & 31,70 \\
Prazo de pagamento & 7 & 7,30 \\
Pós venda & 7 & 7,30 \\
Outros & 2 & 2,40 \\
Entrega rápida & 0 & 0,00 \\
\hline
\end{tabular}

Fonte: Resultados do levantamento (2016).

Por uma segunda vez pode-se observar o respondente valorizando a qualidade do produto revendido. Isso fortalece muito o ponto já evidenciado na Tabela 3. Antes do preço, o cliente está preocupado em ter um produto de qualidade, mesmo que isso lhe custe inicialmente mais caro. Churchill (2010) afirma que a diferenciação do produto ou serviço trará o destaque perante os concorrentes.

As principais características que o vendedor ideal de pneus deve ter, conforme os dados coletados na amostra, estão apresentados na Tabela 5.

Tabela 5 - $\mathrm{N}^{\circ}$ de citações das principais características do vendedor ideal de pneus

\begin{tabular}{lcc}
\hline \multicolumn{1}{c}{ Características } & N $^{\circ}$ Citações & Percentual \\
\hline Conhecimento técnico do produto & 78 & 86,67 \\
Cordialidade & 23 & 25,56 \\
Visitar frequentemente & 16 & 17,78 \\
Fazer pós venda & 9 & 10,00 \\
Boa apresentação & 7 & 7,78 \\
Outros & 2 & 2,22 \\
\hline
\end{tabular}

Fonte: Resultados do levantamento (2016).

Conforme os resultados da Tabela 5, observa-se o grau de importância que o consumidor dá ao conhecimento técnico, considerando o vendedor ideal de pneus, aquele que mais conhecimento tem. O contato pessoal também foi considerado importante pelos respondentes, porém o relacionamento pós- 
venda e a cordialidade do vendedor se manifestaram de forma ainda mais expressiva na pesquisa.

Nesse sentido, Kotlher e Keller (2012) referem-se às pessoas como a alma da organização, pois são o contato com o cliente ou fornecedor, e são elas capazes de causar uma boa ou má impressão da empresa. Ter uma equipe preparada tecnicamente para atender as necessidades do consumidor parece algo obvio, porém não é. O consumidor atual tem mais informação e por esse motivo exige um maior conhecimento e preparo de seu vendedor.

Os serviços que o revendedor ideal de pneus deve oferecer estão apresentados na Tabela 6.

Tabela 6 - Principais serviços que o revendedor ideal de pneus deve oferecer

\begin{tabular}{lcc}
\hline \multicolumn{1}{c}{ Serviços a Serem Prestados } & N $^{\circ}$ Citações & Percentual \\
\hline Serviço de suporte técnico & 26 & 29,30 \\
Serviço de montagem & 25 & 26,80 \\
Veículo Assistência à Frota & 24 & 26,80 \\
Recapagem & 13 & 14,60 \\
Outros & 2 & 2,40 \\
\hline
\end{tabular}

Fonte: Resultados do levantamento (2016).

Tratando-se dos serviços que o revendedor ideal deva oferecer, os mais citados pelos respondentes foram os serviços de montagem de suporte técnico, que são os serviços de suporte ao cliente, onde o técnico ou o vendedor vai até a frota do cliente treinar e dar suporte buscando otimizar os resultados da empresa com o uso de produto. $\mathrm{O}$ terceiro serviço mais citado foi o veículo de assistência a frota, serviço onde o revendedor disponibiliza um Car Service, veículo equipado para fazer serviços de alinhamento e balanceamento dentro da frota do cliente.

A promoção de vendas através de ações que despertem a atenção e interesse do público consumidor sempre foi uma das estratégias do marketing, Kotler (2000). A prestação de um serviço extra ao consumidor desperta seu interesse, capaz de contribuir para o desempenho e a otimização do resultado.

Tratando-se dos motivos que levariam o cliente a trocar de fornecedor, conforme os dados coletados na amostra, estão apresentados na Tabela 7. 
Tabela 7 - $\mathrm{N}^{\circ}$ de citações dos principais motivos que levaria o cliente a trocar de fornecedor

\begin{tabular}{lcc}
\hline \multicolumn{1}{c}{ Possíveis Motivos } & N $^{\circ}$ Citações & Percentual \\
\hline Problema de produto & 52 & 57,10 \\
Mudança de Preço & 24 & 26,20 \\
Falha ou ausência de pós venda & 6 & 7,10 \\
Ausência de visitas do vendedor & 4 & 4,80 \\
Outros & 4 & 4,80 \\
Mudança de vendedor & 0 & 0,00 \\
Falha na entrega & 0 & 0,00 \\
Diminuição prazo de venda & 0 & 0,00 \\
\hline
\end{tabular}

Fonte: Resultados do levantamento (2016).

Conforme os dados apresentados o principal motivo que levaria o cliente a trocar de fornecedor seria um problema de produto. Mais da metade $(57,10 \%)$ dos clientes apontaram que esse seria o principal fator que poderia levá-lo a agir desta forma. Conforme Kotler (2000) deve-se preservar o valor que o produto tem para o cliente para estabelecer uma relação mais longa.

Foi solicitado ao respondente qual a marca de pneus ele recomendaria e os resultados são apresentados na Tabela 8.

Tabela 8 - $\mathrm{N}^{\circ}$ de citações das Marcas que o respondente recomendaria

\begin{tabular}{lcc}
\hline \multicolumn{1}{c}{ Marcas Pneus } & $\mathbf{N}^{\circ}$ Citações & Percentual \\
\hline Michelin & 37 & $40,50 \%$ \\
Pirelli & 33 & $35,70 \%$ \\
Goodyear & 10 & $11,90 \%$ \\
Bridgestone & 4 & $4,80 \%$ \\
Outras & 4 & $4,80 \%$ \\
Continental & 2 & $2,40 \%$ \\
Firestone & 0 & $0,00 \%$ \\
\hline
\end{tabular}

Fonte: Resultados do levantamento (2016).

A marca de pneus mais citada de acordo com a opinião da amostra é a Michelin, com 40,50\% dos respondentes. A segunda marca recomenda foi a Pirelli, com $35,7 \%$ dos respondentes. 


\section{CONSIDERAÇÕES FINAIS}

O principal objetivo deste estudo foi identificar as principais necessidades dos clientes consumidores de pneus Truck no estado do Rio Grande de Sul e quais os principais fatores influenciadores na decisão de compra destes clientes.

Primeiramente foi realizada uma etapa exploratória, por meio de entrevistas em profundidade. Com os resultados dessa primeira etapa, além do referencial utilizado no estudo, foi possível estruturar e realizar a segunda etapa do estudo por meio do levantamento, buscando atender as demandas dos objetivos do estudo.

De acordo com os resultados apresentados, observou-se a importância e relevância dada pelo cliente à qualidade e rendimento do produto. Conforme questionado na pergunta três do estudo, o principal fator influenciador na hora de decidir onde compra foi o rendimento do produto.

Quando perguntado aos respondentes qual a principal característica que o revendedor ideal de pneus deveria ter, a principal resposta foi o produto de qualidade. Outra evidência do estudo é de que os fatores qualidade e rendimento do produto são considerados ainda mais relevantes que o preço do produto.

Outro influenciador identificado foi a importância do fator humano, onde os respondentes identificaram como principal característica do vendedor ideal o conhecimento técnico do produto, seguido pelo pós-venda. Isso mostra que dentre as necessidades do consumidor atual, o conhecimento é o maior deles, pois os clientes buscam além do produto e serviço, o maior número de informações possíveis que possam vir a contribuir no desenvolver de seu trabalho.

Assim, após as colocações em relação ao objetivo geral do estudo, apresentam-se a seguir resultados em relação aos objetivos específicos.

Com relação ao primeiro objetivo específico, buscou-se identificar e compreender as informações coletadas para compreender as necessidades e fatores influenciadores em relação as decisões de compra.

Foi identificado, com base na amostra, que dentre as necessidades consideradas mais importantes por esse público consumidor, o serviço de suporte técnico é uma carência da maioria deles. Este serviço deveria ser fornecido pelo revendedor de pneus e visa mais uma vez levar informação ao consumidor, para que o mesmo possa aplicar em sua frota e obter melhores resultados relacionados à otimização de produto e diminuição de perdas.

Outras necessidades também consideradas importantes pelos respondentes foram o serviço de montagem de pneus e o veículo de assistência à frota, onde ambos deveriam ser fornecidos pelo revendedor. O serviço de recapagem também foi mencionado com menor expressividade, porém por ter sido mencionado tanto nas pesquisas em profundidade quanto no 
levantamento, necessita de uma certa atenção dos gestores, que fornecendo este serviço junto aos mencionados anteriormente, contribuem para um ciclo comercial de vendas dos pneus Truck.

Buscando compreender ainda mais este consumidor, ao questionar os respondentes sobre qual o principal motivo que os levaria a mudar de fornecedor, obteve-se mais uma vez uma grande expressividade de respostas relacionadas a produto, onde os respondentes informaram que a principal causa de mudança de fornecedor seria problema de produto.

De acordo com o segundo objetivo específico, que buscou identificar os principais revendedores de pneus e marcas presentes dentre os consumidores entrevistados, obteve-se a citação de nove fornecedores. Complementando, ainda em referência ao segundo objetivo específico, foram identificadas um total de seis marcas diferentes de pneus: Pirelli, Goodyear, Continental, Michelin, Bridgestone e Firestone.

Finalizando, a principal limitação do estudo foi a impossibilidade de se analisar todos os consumidores de pneus Truck do Estado do RS, sendo que esses podem ou não apresentar as mesmas necessidades e características aqui apresentadas.

\section{REFERÊNCIAS}

ASSOCIAÇÃO NACIONAL DA INDÚSTRIA DE PNEUMÁTICOS (ANIP). Anip em números. [Texto digital]. 2016. Disponível em: <http://www.anip.com.br >. Acesso em: 17 mai. 2016.

CHEMIN, Beatriz F. Manual da Univates para trabalhos acadêmicos: Planejamento, elaboração e apresentação. 3. ed. Lajeado: Univates. 2015. 317 p.

CHIAVENATO, Idalberto. Administração de materiais: uma abordagem introdutória. 1. ed. Rio de Janeiro: Elsevier, 2005.

CHURCHILL, Gilbert A. Jr.; PETER, J Paul. Marketing: criando valor para os clientes. São Paulo: Saraiva, 2010.

GIL, Antônio Carlos. Métodos e técnicas de pesquisa social. 5. ed. São Paulo: Atlas, 1999.

. Como elaborar projetos de pesquisa. 5. ed. São Paulo: Atlas, 2010.

HONORATO, Gilson. Conhecendo o Marketing. São Paulo: Manole, 2004. E-book. Disponível em: <www.univates.br/biblioteca>. Acesso em 27 abr. 2016.

KERIN, Roger A. et al. Marketing. 8. ed. São Paulo: McGraw-Hill, 2007.

KOTLER, Philip. Administração de marketing: análise, planejamento e controle. São Paulo: Atlas, 1974. 
Administração de marketing. São Paulo: Prentice Hall, 2000.

2007.

. Marketing Essencial: conceitos, estratégias e casos. São Paulo: Prentice Hall,

KOTLER, Philip; KELLER, Kevin L. Administração de marketing. 14. ed. São Paulo:

Pearson Education Brasil, 2012.

LAS CASAS, Alexandre Luzzi. Plano de marketing para micro e pequena empresa. 6 . ed. São Paulo: Atlas, 2011.

LEOPARDI, Maria T. Metodologia da pesquisa na saúde. 2. ed. Florianópolis: UFSC, 2002.

MALHOTRA, Naresh K. Pesquisa de marketing: foco na decisão. 3. ed. São Paulo: Pearson, 2011.

SCHIFFMAN, Leon G., KANUK, Leslie L. Comportamento do consumidor. 6. ed. Rio de Janeiro: Editora LTC, 2000.

VERGARA, Sylvia C. Gestão de pessoas. 14. ed. São Paulo: Atlas, 2013. 